DOI: http://dx.doi.org/10.33846/hn40804

http://heanoti.com/index.php/hn

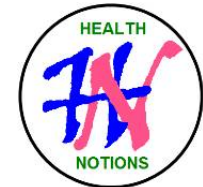

RESEARCH ARTICLE

URL of this article: http://heanoti.com/index.php/hn/article/view/hn40804

\title{
The Correlation Between Weight Increment and Stunting in Children 0-24 Months
}

\author{
Hanna Dyahferi Anomsari ${ }^{1(\mathrm{CA})}$, I Gusti Eka Ayu Pratiwi², Irwanto $^{3}$ \\ ${ }^{1(\mathrm{CA})}$ Department of Pediatrics, Faculty of Medicine, Universitas Airlangga, Indonesia; hannada@gmail.com \\ (Corresponding Author) \\ ${ }^{2}$ Department of Pediatrics, Faculty of Medicine, Universitas Udayana, Bali, Indonesia \\ ${ }^{3}$ Department of Pediatrics, Faculty of Medicine, Universitas Airlangga, Indonesia
}

\begin{abstract}
Globally in 2016, 22.9\% or 154.8 million children under 5 years of age suffered from child stunting. The prevalence of stunting in Indonesia is $19.3 \%$ and in east java it reaches almost $30 \%$. Negative effect of stunting cannot be repair or irreversibel, especially brain damage and the management of stunting is complex, so preventing and reducing child become stunting is more important. Analysis of growth patterns and the detection of aberrant growth patterns provide critical information for the detection of pathologic conditions. Weight-forage is the most commonly used index of nutritional status. Weight loss, or failure to gain normally, is often the first sign of pathology. If routine weight measurements could be used to detect the risk of linear growth faltering, the role of posyandu in stunting prevention could be enhanced. Purpose of this study is to find a relationship of weight increment in 2, 3, 4, and 6 month and stunting in children aged 0-24 months. There was a significant correlation weight increment for 6 months with stunting $(r=-0.432, p=0.004)$
\end{abstract}

Keywords: weight increment; stunting; growth interpretation

\section{INTRODUCTION}

Globally in $2016,22.9 \%$ or 154.8 million children under 5 years of age suffered from child stunting. The prevalence of stunting in Indonesia is $19.3 \%$ and in east java it reaches almost $30 \%{ }^{(1,2)}$. Negative effect of stunting cannot be repair or irreversibel, especially brain damage and the management of stunting is complex, so preventing and reducing child become stunting is more important ${ }^{(3)}$. Stunting in early life - particularly in the first 1000 days from conception until the age of two - impaired growth has adverse functional consequences on the child. Some of those consequences include poor cognition and educational performance, low adult wages, lost productivity and, when accompanied by excessive weight gain later in childhood, an increased risk of nutrition-related chronic diseases in adult life. Linear growth in early childhood is a strong marker of healthy growth given its association with morbidity and mortality risk, non-communicable diseases in later life, and learning capacity and productivity. It is also closely linked with child development in several domains including cognitive, language and sensory-motor capacities. It also affects economic productivity at national level. Women of short stature are at greater risk for obstetric complications because of a smaller pelvis. Small women are at greater risk of delivering an infant with low birth weight, contributing to the intergenerational cycle of malnutrition, as infants of low birth weight or retarded intrauterine growth tend be smaller as adults. Growth is a process rather than a static quality. The analysis of growth patterns and the detection of aberrant growth patterns provide critical information for the detection of pathologic conditions. Calculation of daily and monthly growth, such as weight gain in g/day, allows more precise. The evaluation for any child who is not growing well includes a careful analysis of growth charts. A review of the growth pattern over time is the most useful. Weight-for-age is the most commonly used index of nutritional status. Weight-for-age has the advantage of being somewhat easier to measure than indices that require height measurements. Weight loss, or failure to gain normally, is often the first sign of pathology ${ }^{(2)}$. Measurement two consecutive increments below specified thresholds as an approach to detecting risk. Weight-for-age charts that velocity below P5 in 2 successive months would identify $0.5-2 \%$ of infants as failing to thrive ${ }^{(3)}$. Analysis of growth patterns and the detection of aberrant growth patterns provide critical information for the detection of pathologic conditions. Weight-for-age is the most commonly used index of nutritional status. Weight loss, or failure to gain normally, is often the first sign of pathology ${ }^{(2)}$. Measurement and recording of body weight in Indonesia is carried out at Posyandu by female 
cadres. Understanding the interpretation of the growth curve is very important, If routine weight measurements could be used to detect the risk of linear growth faltering, the role of posyandu in stunting prevention could be enhanced. Purpose of this study is to find a relationship of weight increment in 2,3,4, and 6 month with stunting in children aged 0-24 months.

\section{METHODS}

This was a retrospective cohort study. The subjects of the study were children aged 6-24 months who came to the posyandu, where their weight and height were measured at that time. Weight increment/gain was calculated using a table obtained from WHO, with weight gain less than 25 said to be abnormal. Stunting when the time of measurement of height is below -2 SD on the WHO curve. Data were analyzed using correlation Pearson.

\section{RESULTS}

Table 1 shows the characteristics of the subjects, there were 44 children who met the criteria. As many as 25 boys $(56.8 \%)$, aged more than 12 months as much as $61.4 \%$, exclusive breastfeeding was $45.5 \%$. The age of 6 months was the most age at starting complementary feeding $(63.6 \%)$. There were $38.6 \%$ cases of stunting from the number of samples obtained.

Table 1. Characteristic of the subject

\begin{tabular}{lc}
\hline Characteristic & $\mathrm{n}(\%)$ \\
\hline Sex & \\
\hline Male & $25(56.8)$ \\
\hline Female & $19(43.2)$ \\
\hline Age & $17(38.6)$ \\
\hline 6-12 months & $27(61.4)$ \\
\hline 12-24 months & $8(18.2)$ \\
\hline Age of complementary food & $28(63.6)$ \\
\hline$<6$ months & $8(18.2)$ \\
\hline 6 months & \\
\hline Nutrition before 6 months old & $20(45.5)$ \\
\hline Exclusive breastfeeding & $18(40.9)$ \\
\hline Partial breastfeeding & $6(13.6)$ \\
\hline Formula & $17(38.6)$ \\
\hline Stunted
\end{tabular}

Table 2. Correlation between weight increment and stunting

\begin{tabular}{ccc}
\hline Variable & $\mathrm{r}$ & $\mathrm{p}$ \\
\hline Weight increment 2 months & -0.162 & 0.295 \\
\hline Weight increment 3 months & -0.119 & 0.443 \\
\hline Weight increment 4 months & -0.321 & 0.321 \\
\hline Weight increment 6 months & $\mathbf{- 0 . 4 3 0}$ & $\mathbf{0 . 0 0 4 *}$ \\
\hline
\end{tabular}

There was relationship between weight increment and stunting with value $p=0.004$ and $r=-0.430$ with negative relationship direction. This means when weight was not increment (decrease) in 6 months, stunting will increase.

\section{DISCUSSION}

Posyandu program is supported by Indonesia's government and held every month in every village level. The operations of Posyandu is supported by cadre or village health volunteers. Since 1970, Posyandu used Kartu Menuju Sehat (KMS) / Card Towards Healthy to record and monitor the growth of under-five children based on weight-for-age indicator. The latest KMS that has been revised in 2008 provides growth charts based on WHO Anthropometric Standard 2005, also contains data about weighing time, and the minimum standard of weight gain per month ${ }^{(4)}$. Weight gain for 6 months is associated with the incidence of stunting, this is the same as this study and a study conducted in Congo states that low weight gain at 3-6 months is very real in children with stunting ${ }^{(5)}$. Growth during the first quarter of infancy was an important determinant for development of malnutrition at older ages ${ }^{(5)}$. Gambia support earlier research that showed that being weight faltering in long time increases the risk of subsequently becoming stunted, These associations indicate that the body responds to 
weight faltering by slowing linear growth ${ }^{(6)}$. Long term weight faltering can be response to linear growth faltering ${ }^{(5)}$. Poor weight gain may precede linear growth retardation perturbations in the weight acquisition process can have a lasting impact on linear growth ${ }^{(7)}$. Stunting is in part a biological response to previous episodes of being undernutrition. This finding suggests that stunting may represent a deleterious form of adaptation to more overt undernutrition ${ }^{(8)}$. Stunting is considered to be a result of chronic malnutrition, exacerbated by frequent infections, especially diarrhoea ${ }^{(9)}$. Chronic malnutrition is most often identified by a faltering height-for-age and affects long-term growth as a result of chronic nutrition deficiency. The distinction between acute and chronic illness is based on time, chronic as a dcondition that lasts 3 months or longer. Chronic malnutrition may be characterized by stunting (decreased height velocity). This is a characteristic of chronic malnutrition that may be irreversible and manifest earlier than 3 months if nutrient deficiency is severe $^{(10)}$. That is important to observation weight increment because long term weight faltering can increased risk of stunting.

\section{CONCLUSION}

Knowing weight increment is important to prevent stunting

\section{REFERENCES}

1. Kemenkes RI. Basic Health Research 2018 (Riset Kesehatan Dasar 2018). Jakarta: Kemenkes RI; 2018.

2. Brannsether B, Eide GE, Roelants M, Bjerknes R, Júlíusson PB. BMI and BMI SDS in childhood: annual increments and conditional change. Annals of Human Biology. 2017;44(1):28-33.

3. Onyango AW, Borghi E, de Onis M, Frongillo EA, Victora CG, Dewey KG, et al. Successive 1-month weight increments in infancy can be used to screen for faltering linear growth. Journal of Nutrition. 2015; 145(12):2725-31.

4. Ohyver M, Moniaga J V., Yunidwi KR, Setiawan MI. Logistic Regression and Growth Charts to Determine Children Nutritional and Stunting Status: A Review. Procedia Computer Science. 2017;116:232-41.

5. Simondon KB, Simondon F, Cornu A, Delpeuch F. The utility of infancy weight curves for the prediction of linear growth retardation in preschool children. Acta Paediatrica Scandinavica. 1991;80(1):1-6.

6. Wells JCK, Briend A, Boyd EM, Berkely JA, Hall A, Isanaka S, et al. Beyond wasted and stunted-a major shift to fight child undernutrition. The Lancet Child and Adolescent Health. 2019;3(11):831-4.

7. Richard SA, Black RE, Gilman RH, Guerrant RL, Kang G, Rasmussen ZA, et al. Wasting Is Associated with Stunting. The Journal of Nutrition. 2012;1291-7.

8. Schoenbuchner SM, Dolan C, Mwangome M, Hall A, Richard SA, Wells JC, et al. The relationship between wasting and stunting: A retrospective cohort analysis of longitudinal data in Gambian children from 1976 to 2016. American Journal of Clinical Nutrition [Internet]. 2019;110(2):498-507. Available from: http://dx.doi.org/10.1093/ajcn/nqy326

9. Ngari MM, Iversen PO, Thitiri J, Mwalekwa L, Timbwa M, Fegan GW, et al. Linear growth following complicated severe malnutrition: 1-year follow-up cohort of Kenyan children. Archives of Disease in Childhood. 2019;104(3):229-35.

10. Mehta NM, Corkins MR, Lyman B, Malone A, Goday PS, Carney L, et al. Defining pediatric malnutrition: A paradigm shift toward etiology-related definitions. Journal of Parenteral and Enteral Nutrition. 2013;37(4):460-81. 